\section{Are New Devices for Percutaneous Dilatational Tracheostomy Really Needed? Yes}

\section{To the Editor:}

We read with interest the comments and suggestions of Dr Sangwan; however, a number of the issues he raised need to be clarified. A fiberoptic bronchoscope is commonly used during percutaneous dilatational tracheostomy (PDT) throughout Europe. ${ }^{1}$ Recent surveys performed in Germany, Italy, and the United Kingdom report that a fiberoptic bronchoscope is used to guide PDT in $\sim 90 \%$ of national ICUs. ${ }^{2}$ The use of a bronchoscope is recommended and may add safety during PDT by recognizing anatomical landmarks, guiding procedural steps, and confirming the correct positioning of the cannula. ${ }^{3,4}$ The aim of a double lumen endotracheal tube (DLET) is to minimize impairment of ventilation and gas exchange during PDT. ${ }^{5,6}$

Ultrasound neck evaluation is increasingly used as a screening tool before PDT to assess at-risk anatomical structure and to prevent puncture of vessels and bleeding. ${ }^{1}$ However, although ultrasound-guided PDT has been recently proposed, current data do not suggest that ultrasound should replace bronchoscopy. If vascular injury should occur during the procedure, the presence of the distal cuff of the DLET protects the lung from blood aspiration and maintains stable ventilation. ${ }^{6}$ Contrary to the use of the DLET, the procedure suggested by Dr Sangwan to avoid puncture of the posterior tracheal wall requires an operator skilled in ultrasound. ${ }^{7}$

The use of a pediatric fiberoptic bronchoscope during PDT reduces the diameter of the endotracheal tube (ETT) and the delivered tidal volume. ${ }^{8}$ The DLET avoids any reduction in the diameter of the ETT, allowing bronchoscopy completely independent from ventilation. The DLET may be used with a fiberoptic bronchoscope that is $\leq 5 \mathrm{~mm}$ in external diameter. Dr Sangwan proposes the use of an Easy Tracheostomy (EZT) with a proximal cuff serving as a locking mechanism. ${ }^{9}$ The EZT combines an extraglottic with the conventional subglottic ETT. The placement of the EZT may be difficult in patients with a narrow glottis. Furthermore, critically ill patients frequently have a narrowing of the airway due to prolonged or repeated intubations. We believe that the DLET is easier to use than the EZT, at least in select patients. ${ }^{6}$ Our recent papers are the first in vitro 5 and in $v^{1} 0^{6}$ studies of the use of the DLET during PDT.

Maria Vargas MD Giuseppe Servillo MD

Department of Neuroscience and

Reproductive and Odontostomatological Sciences

University of Naples "Federico II" Naples, Italy

Paolo Pelosi MD

Department of Surgical Sciences and Integrated Diagnostics

Istituto di Ricovero e Cura a Carattere Scientifico

Azienda Ospedaliera Universitaria San Martino IST

University of Genoa Genoa, Italy

Robert M Kacmarek RRT PhD FAARC

Department of Anesthesiology and Critical Care

Department of Respiratory Care Massachusetts General Hospital Boston, Massachusetts
The authors have disclosed no conflicts of interest.

DOI: $10.4187 /$ respcare. 04232

\section{REFERENCES}

1. Vargas M, Pelosi P, Servillo G. Percutaneous tracheostomy: it's time for a shared approach! Crit Care 2014;18(4):448.

2. Vargas M, Servillo G, Arditi E, Brunetti I, Pecunia L, Salami D, et al. Tracheostomy in intensive care unit: a national survey in Italy. Minerva Anestesiol 2013;79(2):156-164.

3. Putensen C, Theuerkauf N, Guenther U, Vargas M, Pelosi P. Percutaneous and surgical tracheostomy in critically ill adult patients: a meta-analysis. Crit Care 2014;18(6):544.

4. Brunetti I, Pelosi P. Ultrasound and bronchoscopic guided percutaneous dilatational tracheostomy: friends for life! Minerva Anestesiol 2015;81(2):119-121.

5. Vargas M, Servillo G, Tessitore G, Aloj F, Brunetti I, Arditi E, et al. Double lumen endotracheal tube for percutaneous tracheostomy. Respir Care 2014;59(11):1652-1659.

6. Vargas M, Pelosi P, Tessitore G, Aloj F, Brunetti I, Arditi E, et al. Percutaneous dilatational tracheostomy with a double-lumen endotracheal tube: a comparison of feasibility, gas-exchange and airway pressure. Chest 2015;147(5):1267-1274.

7. Sangwan YS. Defining an ideal technique for PDT-is real-time ultrasound guidance the final piece of the puzzle? J Crit Care 2015;30(2):429.

8. Hsia D, DiBlasi RM, Richardson P, Crotwell D, Debley J, Carter E. The effect of flexible bronchoscopy on mechanical ventilation in a pediatric lung model. Chest 2009;135(1):33-40.

9. Sangwan YS, Koveleskie J, Palomino J, Simeone F. A new endotracheal tube designed to enable a single operator to perform percutaneous dilatational tracheostomy while maintaining the airway, providing continuous bronchoscopic guidance, and minimizing procedural complications. J Bronchology Interv Pulmonol. 2011;18(4):368-373. 